\section{Estudo \\ Ecidebate}

em Testão

Planejamento
Revista Estudo \& Debate, Lajeado, v. 27, n. 4, 2020. ISSN 1983-036X

DOI: http://dx.doi.org/10.22410/issn.1983-036X.v27i4a2020.2589

\title{
TEORIA DOS DESEQUILÍBRIOS REGIONAIS E A HIPÓTESE DE CONVERGÊNCIA DO DESENVOLVIMENTO PARA AS REGIÓES BRASILEIRAS
}

\author{
Denis Fernandes Alves ${ }^{1}$
}

\begin{abstract}
Resumo: Historicamente, estudos sobre desequilíbrios regionais têm sido fundamentais para a compreensão do processo de crescimento e desenvolvimento local, regional e nacional. Nesse sentido, o presente artigo teve como objetivo mensurar os desequilíbrios intra e inter-regionais brasileiros nas últimas três décadas e analisá-los a partir da hipótese de convergência do desenvolvimento introduzida por Williamson (1965). Para tanto, foram utilizadas variáveis censitárias da populaçáo nacional e dos estados brasileiros, além da variável renda per capita nos anos de 1991, 2000 e 2010. Os dados, de natureza secundária, foram extraídos do Censo Demográfico, disponibilizado pelo Instituto Brasileiro de Geografia e Estatística (IBGE). Com o objetivo de capturar traços de redução ou expansão das desigualdades intra e inter-regionais no território brasileiro, utilizando o índice de Williamson. Observou-se que, na escala das grandes regiôes, houve uma queda acentuada - na década de 2000 - das desigualdades regionais. Isso representa uma renda per capita nacional mais alta, bem como uma queda na concentração de renda. No entanto, de forma intra regional, houve um aumento nas disparidades presentes nos territórios das regiōes Norte e Centro-Oeste, enquanto nas regióes Nordeste, Sul e Sudeste houve uma queda no indicador. Portanto, pode-se concluir que a hipótese de convergência do desenvolvimento regional em algumas regiốes não é rejeitada em comparaçáo com outras no período do estudo.
\end{abstract}

Palavras-chave: Desigualdades regionais; Convergência do desenvolvimento; Índice de Williamson.

\section{THEORY OF REGIONAL IMBALANCES AND THE CONVERGENCE HYPOTHESIS OF DEVELOPMENT FOR BRAZILIAN REGIONS}

\begin{abstract}
Historically, studies on regional imbalances have been fundamental for understanding the process of growth and local, regional and national development. In this sense, the present article aimed to measure the Brazilian intra and interregional imbalances in the last three decades and analyze them starting from the hypothesis of convergence of development introduced by Williamson (1965). For this, census variables from the national population and from Brazilian states were used, in addition to the per capita income variable in the years 1991, 2000 and 2010. The data, of a secondary nature, were extracted from the Demographic Census, made available by the Brazilian Institute of Geography and Statistics (BIGS). With the aim of capturing traces of
\end{abstract}

1 Doutorando em Economia pelo Programa de Pós-Graduação em Economia da Universidade Federal de Pernambuco (PIMES/UFPE). Mestre em Economia pelo PPECO/UFRN. E-mail: denis_fernandes@ outlook.com 
reduction or expansion of intra and interregional inequalities in Brazilian territory using the Williamson Index. It was observed that, in the scale of large regions, there was a sharp drop - in the 2000s - of regional inequalities. This represents a higher national per capita income, as well as a drop in income concentration. However, in an intraregional way, there was an increase in the disparities present in the territories of the North and CenterWest regions, while in the Northeast, South and Southeast there was a drop in the indicator. Therefore, it can be concluded that the hypothesis of convergence of regional development in some regions is not rejected in comparison with others in the study period.

Keywords: Regional inequalities; Convergence of development; Williamson index.

\section{Introdução}

Historicamente, os estudos que versam sobre os desequilíbrios regionais são fundamentais para compreensão do processo de crescimento econômico e desenvolvimento de uma determinada nação. Sabe-se que o curso desses processos é, por vezes, geograficamente desigual, com inúmeros desdobramentos nos seus aspectos econômicos, sociais, ambientais, culturais e políticos.

A forte relação que se tem entre o estudo dos desequilíbrios regionais ou desajustes regionais com a economia é bastante enfatizada no campo de estudo da Economia Regional. Para a qual autores clássicos como Von Thünen, Alfred Weber, August Lösch, François Perroux e Walter Isard, dentre outros, emerge estudos e investigaçôes sobre o processo de localização das atividades produtivas. O destaque tem sido a busca de uma lógica para a localização das atividades econômicas provocando efeitos diferenciados do ponto de vista regional e de sua dinâmica (ISARD, 1956; 1975; HADDAD et al., 1989; SILVA et al., 2014).

Nas últimas décadas, tem crescido bastante o interesse por análises, em diversas escalas, dos desequilíbrios regionais, priorizando, sobretudo, os aspectos econômicos e sociais. Logo, a existência desses desajustes em um determinado momento e quase sempre tomados em um contexto nacional, decorrem de vantagens econômicas e sociais, produzidas historicamente, mais favoráveis a determinadas regiōes do que a outras (SILVA et al., 2014). Isso acontece principalmente no processo inicial de desenvolvimento econômico das regióes, que é quando começa se estruturar o setor industrial com formação e ampliação de uma rede de comércio e serviços, logo chegando a desenvolver-se. Na teoria desenvolvida por Williamson (1965), este acredita que há um processo de convergência do desenvolvimento das regiōes.

Quando desenvolvidas, a convergência entre as regióes se tornaria a regra. Ou seja, os desequilíbrios regionais existiriam apenas durante os estágios iniciais do processo de desenvolvimento. Nas fases mais avançadas, naturalmente ocorreria a tendência ao equilíbrio. Esta ideia de que as desigualdades sociais e regionais diminuiriam naturalmente com o crescimento econômico revelou-se absolutamente falsa no Brasil na visão de Silva et al. (2014). Já que, segundo Pereira (2018), o sistema capitalista brasileiro, retardatário e atrasado, não promoveu um desenvolvimento equilibrado, provocando desigualdades regionais e sociais gravosas.

Assim, mensurar os desequilíbrios regionais de um país, é um relevante dever da economia regional. No caso do Brasil, dado o seu passado histórico de concentração industrial 
no Centro-Sul, sobretudo em Sáo Paulo, estudos como este devem ser encarados como uma prioridade, em diferentes escalas de análise, como decorrência de sua enorme dimensão espacial/continental e de suas diversificadas histórias, geografias e economias regionais. $\mathrm{O}$ que faz levantar o seguinte questionamento: Será que com o processo de desenvolvimento da economia brasileira ao longo dos anos, pode-se considerar que esteja ocorrendo uma convergência do desenvolvimento? E se acontece, será que essa convergência ocorre tanto a nível inter-regional quanto a nível intra regional?

É partindo dessas questôes que o presente artigo tem como objetivo geral investigar e mensurar o processo de desequilíbrios inter e intra regionais brasileiros nas últimas décadas. Analisando como foi o comportamento das regiốes e, de um modo geral, entre as regióes.

A hipótese que orienta o estudo é a de convergência do desenvolvimento introduzida por Williamson (1965). Que diz que: "os estágios iniciais de desenvolvimento criam diferenciais de renda em que algum ponto deste curso, algumas ou todas às tendências desequilibradoras diminuem, causando uma reversão no padrão de desigualdade interregional" (WILLIAMSON, 1965, p. 62). Analisando pela ótica da distribuição de renda per capita, ao utilizar dados dos Censos Demográficos do IBGE para os anos de 1991, 2000 e 2010. Optou-se por esse recorte temporal justamente para investigar esses desajustes no período recente, e se indicam possíveis mudanças estruturais.

O presente artigo traz uma contribuição metodológica para o estudo da desigualdade regional em longo prazo. A aplicação do índice de Williamson - com base teórica consolidada na literatura nacional e internacional - a variáveis censitárias, assim o artigo objetiva capturar mudanças no padrão de desenvolvimento nacional e nas características socioeconômicas, acabam por proporcionar uma macrovisão sobre a problemática da desigualdade regional no Brasil. Além de identificar fatores essenciais e indispensáveis para se pensar em políticas de desenvolvimento regional.

Para além desta introdução, o artigo encontra-se estruturado com outras cinco seções. A segunda seção trata das principais teorias relativas aos desequilíbrios regionais, a seçáo seguinte expóe o caso brasileiro desde o limiar do século XX. A seção quatro, representa o procedimento metodológico utilizado na pesquisa. A seção cinco apresenta os principais resultados encontrados e sua discussão na literatura. E, por fim, têm-se as consideraçóes finais do estudo.

\section{Consideraçóes sobre as teorias dos Desequilíbrios Regionais}

Compreende-se que a ausência de um vínculo econômico entre as regióes nos estágios iniciais de crescimento nacional, provocam gravosos problemas de desequilíbrios regionais a longo prazo no país. Isto é, uma grande parte do processo de crescimento nacional é advinda da própria unificação econômica dos mercados regionais. Posto isto, os economistas regionais, há muito, reconhecem a existência e persistência do chamado "Dualismo Regional", comum em todos os níveis de desenvolvimento nacional (WILLIAMSON, 1965). Além disso, a persistência do dualismo ao longo da experiência histórica de quase todos os pais desenvolvidos da atualidade. 
Segundo Williamson (1965) as discussões teóricas cada vez mais ativas, pesquisa empírica e, principalmente, preocupaçáo política com esse aspecto do crescimento econômico deram aos fenômenos de desequilíbrio ou desigualdades regionais um novo termo popular - o "Problema Norte-Sul". Assim, se se desenvolve uma nação mais regionalizada, permanece exposta aos efeitos adversos da polarizaçáo do crescimento. Por exemplo, se existe uma regiáo Norte que possui uma área agrícola grande e produtiva, sobretudo em relação à região Sul, logo, o Sul, nesse contexto, será em grande parte cortado dos retornos benéficos e do desenvolvimento, em uma escala maior e mais rápida, do Norte. Esse fator deve ajudar a explicar os problemas relativamente severos da relaçáo Norte-Sul, uma Dualismo Regional ou economias dualistas. O dualismo sulista (prevalecendo no Sul do país o desenvolvimento) persistiu, por exemplo, nas histórias do Nordeste brasileiro, do Oriente da Colômbia, do Mezzogiorno da Itália e do Sul dos EUA.

$\mathrm{Na}$ Itália, por exemplo, um dos mais famosos casos de dualismo regional no mundo, entre as regiōes Norte e Sul, é advindo antes da própria unificação nacional. Assim como Fargion (2004), Galvão (2016) observou que a incursão pela história italiana remonta que as origens mais profundas dos desequilíbrios entre o Norte e o Sul têm início algumas décadas antes da unificação. Esse período que antecede à unificação do país, ocorrida no ano de 1861, integrou regióes com profundas diferenças econômicas e socioculturais e que essas diferenças se exacerbaram ainda mais após a unificação. Perdurando até o início da década após a Segunda Grande Guerra, quando tiveram início as políticas de intervençáo extraordinária para redução das desigualdades regionais (GRIBAUDI, 1997; FARGION, 2004; GALVÃO, 2016).

Bercovici (2003, p. 98) salienta que "para seus críticos, a análise dualista equivocava-se ao descrever uma oposição formal entre os setores "modernos" e "atrasados" economicamente". Em um país, tais diferenças regionais não significariam a existência de sistemas econômicos distintos, contudo revelavam traços e níveis diferentes de integraçáo ao sistema econômico nacional como um todo.

Em termos conceituais, podemos estabelecer a relação entre desequilíbrios regionais e o processo de integraçáo regional. Este último, consiste em um conjunto de medidas de caráter econômico e comercial que têm por objetivo promover a aproximaçáo e, eventualmente, a união entre as economias de duas ou mais regiôes. Essa aproximação em termos econômicos da estrutura produtiva, estabelece um processo de convergência do desenvolvimento econômico regional o que, consequentemente, impacta positivamente na redução das disparidades presente no território. Teoria sob a qual Williamson (1965) fundamentou sua contribuição seminal de hipótese de convergência do desenvolvimento.

Para Williamson (1965, p. 7-8), "na medida em que esses vínculos inter-regionais são lentos no desenvolvimento, é mais provável que o desenvolvimento nacional seja regionalizado nos estágios iniciais do crescimento". Desse modo, Williamson (1977) destaca sua hipótese e por seu método de análise, de validade internacional, com amplo significado histórico. Sua hipótese era a seguinte:

A hipótese inicial desse estudo é que os estágios iniciais do desenvolvimento nacional criam diferenciais de renda entre o Norte e o Sul [a região mais rica e a mais pobre] 
cada vez maiores. Em algum ponto do curso do desenvolvimento, algumas ou todas as tendências desequilibradoras diminuem, causando uma reversão no padrão de desigualdade inter-regional. Ao invés da divergência dos níveis inter-regionais de desenvolvimento, a convergência será preponderante, com as regióes atrasadas diminuindo o hiato de desenvolvimento entre elas e as áreas industrializadas. O resultado esperado é que a descrição estatística da desigualdade regional tenha a forma de um $\boldsymbol{U}$ invertido, ao longo do curso do crescimento nacional; o momento histórico do máximo de desigualdade espacial é um tanto quanto vago, e pode variar consideravelmente com a dotaçáo de recursos e o ambiente institucional de cada nação em desenvolvimento (WILLIAMSON, 1977, p.62).

Além da teoria da convergência do desenvolvimento há uma série de outras amplamente difundidas na literatura que investigam e propõe soluções para as desigualdades regionais como Baldwin (1956), Vietorisz (1967), Myrdal (1966), Richardson (1980) e Hind (1984). De modo mais simples alguns autores afirmam que as disparidades são temporárias e essas desigualdades emergem em decorrência da ausência unificaçáo econômica das economias regionais, geradas pelo fato de a expansão do desenvolvimento ocorrer de forma regionalizada nos primeiros estágios. Ao longo do tempo iria se reduzindo os efeitos dos elementos causadores das desigualdades regionais, pois todo o sistema econômico nacional tenderia ao equilíbrio. Nesta fase do desenvolvimento, a convergência entre as regióes se tornaria a regra, conforme Williamson (1965). Já nas fases mais avançadas, naturalmente ocorreria a tendência ao equilíbrio.

Por sua vez, Perroux $(1955 ; 1977)$ definiu o fenômeno da polarização e suas repercussóes afirmando que o crescimento não surge em todos os lugares ao mesmo tempo. $\mathrm{Na}$ realidade ele se manifesta em pontos ou polos de crescimento, com intensidade variáveis, o crescimento se transmite através de diversos canais e com efeitos variáveis para o conjunto da economia. Apesar das suas contribuiçóes positivas à teoria, não trata as desigualdades regionais como um processo político e econômico onde a estrutura de poder, transferência de poupanças e desigualdades implícitas nas relaçóes inter-regionais, aparentemente iguais ou equivalentes, têm importância fundamental (COUTINHO, 1973; SILVA; LIMA; PIFFER, 1999).

Silva (2009) destaca que como em outras teorias, a teoria dos polos de crescimento não está isenta de críticas. Uma delas, feita por Blaug (1977), este acredita que Perroux (1977) exagerou na ambição de tentar explicar completamente o funcionamento da economia e critica o fato dele defender a dominaçáo através da criaçáo de polos como elemento essencial na busca do desenvolvimento regional. O que leva a crer que seria o modelo ideal para o desenvolvimento, muito embora com desigualdades regionais acentuadas.

Pela teoria de Baldwin (1956), o chamado modelo da base econômica com diferenciação interna, tem como um dos objetivos distinguir a economia de minifúndios e plantation. De modo que a economia de minifúndios não só tenderia a originar uma industrialização endógena como também teria menor tendência a desigualdades espaciais, com o desenvolvimento "equilibrado" de um sistema urbano dentro da distribuição lognormal. Já o plantation deixaria como herança forte tendência ao desequilíbrio regional, uma vez que todo o sistema voltado para a exportaçâo reforçaria em excesso a cidade central (em geral porto marítimo), sede dos negócios e da vida das classes dominantes (BALDWIN, 1956; COUTINHO, 1973). 
Myrdal (1966) foi pioneiro a perceber e ressaltar a natureza autocumulativa das desigualdades regionais como um processo dificilmente reversível em qualquer sistema econômico, face aos mecanismos de causação circular. Ao passo que a teoria de Vietorisz (1967), representa uma crítica à ajuda externa através de empréstimos em favor da intensificação do comércio, o chamado modelo de trade-not aid. Segundo Vietorisz (1967), se o comércio fosse incentivado por meio de uma maximizaçáo planejada das vantagens comparativas de cada região com autofinanciamento dos investimentos, numa perspectiva de longo prazo. Isto é, ao invés de predicar a transferência de fundos entre regióes ricas e pobres sob a forma de empréstimos, propóe-se uma divisão de atividades produtivas entre as regiōes como intensificação do comércio, de forma que cada regiāo especializar-se-ia nos setores onde possui vantagens comparativas de longo prazo. Merhav (1970) acredita que a dependência tecnologia, sendo importada de modo intensivo em capital físico e operando com grandes escalas para os mercados das regióes mais atrasadas, tende a concentrar os setores industriais. A renda concentra-se náo somente do ponto de vista funcional, mas também acentuaria significativamente as desigualdades intra regionais (COUTINHO, 1973).

Richardson (1980), por sua vez, desenvolve a ideia de Reversão da Polarização (RP). Em que a RP pode ser definida como o ponto de virada, que é quando as tendências de polarização espacial na economia nacional dão lugar a um processo de dispersão espacial da região central para outras regióes do sistema. Assim, o processo industrial urbano de desenvolvimento nacional começa em apenas uma ou duas regiōes, principalmente devido à escassez de recursos de investimento. A escolha das regiōes é determinada pelas vantagens iniciais da localização (doaçôes de recursos ou um importante recurso imóvel, como um porto) ou porque foi a primeira área aberta do lado de fora (e isso eventualmente se converte no tamanho de mercado maior da cidade de primatas ex-colônias).

Tais vantagens tornam-se um processo cumulativo de causalidade, explicado pelo aumento dos retornos de escala e a consequente polarização do trabalho e qualquer excesso de capital de outras regiōes. A relação núcleo-periferia é assim estabelecida, onde a região central, que consiste na cidade primata e em seu interior, domina o restante da economia regional, denominada periferia. Essa periferia é dominada pelo núcleo e depende dele, e sua taxa de desenvolvimento é controlada e distorcida para promover os interesses econômicos do núcleo (RICHARDSON, 1980).

Outra tese que deve ser destacada na análise das desigualdades regionais é a do colonialismo interno. As teorias do colonialismo interno, foram mais difundidas na literatura a partir da década de 1960 e eram aplicadas no estudo de sociedades com experiência colonial, onde as relaçooes entre metrópole e colônia poderiam ser consideradas paralelas às relaçôes sociais desenvolvidas internamente. A ideia, na versão inicial de Hind (1984), destacava a analogia das relaçóes vigentes no antigo sistema colonial com a existência de setores "colonizadores" e setores "colonizados" convivendo na mesma sociedade nacional. Algumas características da existência do colonialismo interno seriam a sujeição política, exploração econômica, dominação cultural e conflitos raciais (HIND, 1984).

De acordo com Monasterio (2014), uma miríade de estudos de convergência de renda per capita mostra resultados não táo consensuais sobre a tendência da desigualdade regional 
entre os estados. Logo, os desequilíbrios regionais, analisando os aspectos econômicos e sociais existentes em um determinado momento e quase sempre tomados em um contexto nacional, decorrem de vantagens econômicas e sociais, produzidas historicamente, mais favoráveis a determinadas regiôes do que a outras (SILVA et al., 2014).

Dessa forma, emerge uma nova percepção de que o processo de crescimento ou desenvolvimento de uma nação é geograficamente desigual, com inúmeros desdobramentos no setor econômico, social, cultural e político de um país. Países de dimensão espacial de grandes proporçôes como é o caso do Brasil os desequilíbrios regionais tendem a ser mais problemáticos.

De acordo com Gama e Baracho (2014), muito embora às influências de Perroux, Myrdal e Hirschman, tenham sido essenciais, a teoria que fundamentou efetivamente a política brasileira de desenvolvimento regional foi a teoria do subdesenvolvimento da Comissão Econômica para a América Latina e o Caribe (CEPAL). Já que a reversão espontânea do processo de concentração regional de renda é praticamente impossível. E, sendo assim, a integração econômica não planejada leva ao agravamento dos desequilíbrios regionais, é necessária uma política nacional de desenvolvimento regional.

Essa solução exigirá uma nova forma de integração da economia nacional, distinta da simples articulação que se processou na primeira metade do século, conforme explanado por Cano (1985). Segundo Bercovici (2004) e Gama e Baracho (2014) a Questấo Regional é uma questão diretamente ligada ao Estado brasileiro. Além de envolver aspectos concorrentes à própria forma de Estado (o federalismo), sua resoluçáo passa pelo poder político e pelas políticas públicas que afetam a distribuição territorial de renda no Brasil. Assim, as desigualdades regionais devem ser entendidas como fator da política e produto político, pois são consequências de ações políticas e impõem decisões políticas, influenciando na necessária elaboração de um projeto nacional de desenvolvimento (CASTRO, 1992; GAMA; BARACHO, 2014).

\section{Desequilíbrios Regionais Brasileiros}

No caso brasileiro, os desequilíbrios regionais se acentuaram com maior nitidez no momento em que se intensificou o processo de industrialização nacional. Segundo Cano (1985) esse processo pode ser compreendido em dois momentos distintos de 1930 a 1955 , quando se altera o padrão de acumulação de capital e ingressamos na industrializaçáo restringida, e 1956-70, quando o padrão se altera e são implantadas as indústrias produtoras de bens de produção e consumo durável, a chamada industrialização "pesada". Essa análise permitiu concluir que os efeitos de estímulo ao desenvolvimento industrial superaram largamente os de "destruição".

Pereira (2015) entende que a descentralização produtiva no Brasil se caracterizou por ser mais uma realocação industrial do que uma descentralização de capitais. Segundo o autor, isso se deve ao fato que a descentralizaçáo do principal centro produtor brasileiro, São Paulo, ter ocorrido, em grande parte, dentro do próprio estado. Assim as indústrias realocaram algumas de suas filiais para cidades interioranas, no entanto estas se apresentavam como pontos estratégicos, próximas à capital ou a Regiáo Metropolitana de São Paulo. 
No entanto, esses processos de desconcentração industrial no Brasil, sempre tiveram o incentivo do Estado, seja por meio de políticas econômicas ou mesmo de projetos e programas de outras instituiçóes derivadas da União. Para Bercovici (2004) o Estado brasileiro é o principal promotor do desenvolvimento e, em virtude disso, terá que lidar com problemas ligado a formação do Estado nacional: as desigualdades regionais. A existência dessas desigualdades é um problema da sociedade nacional como um todo, não apenas dos residentes nas regióes menos desenvolvidas. Para Furtado (1982) e Bercovici (2004) os grandes problemas nacionais só podem ser estudados corretamente se levarem em consideração os desequilíbrios regionais.

A fase da Indústria Restringida, é assim denominada por conta que a reprodução do capital dependia do setor externo e da capacidade de importar. É nessa fase, que há a consolidação da posição hegemônica do capital produtivo industrial, extremamente concentrado num espaço regional restrito, o Centro Sul (mais especificamente Sáo Paulo). Esse processo de concentração regional acontece e agrava cada vez mais as desigualdades regionais, assim coube as demais regióes passarem estimular e a dinamizar suas atividades produtivas como forma de se inserir no mercado nacional (ALVES, 2020).

O processo de industrialização pesada brasileira teve início com maior consistência no Governo de Juscelino Kubistchek (JK), iniciada na segunda metade da década de 1950. Essa última etapa, da periodizaçáo tomou proveito do momento internacional favorável. Durante esse período já era visível a forte concentraçáo, no Centro-Sul, dos setores dinâmicos da estrutura produtiva nacional. O problema do desajuste regional surge assim, com intensidade, neste momento em função da unificação dos mercados nacionais. Deste modo, é promovido o chamado hiato econômico entre o Centro-Oeste, Norte e Nordeste com as regióes do Sul e Sudeste brasileiro (concentrando o dinamismo econômico-produtivo sobretudo em Sáo Paulo). Característico de economias dualistas (CANO, 2008; ALVES, 2020).

Os dados apontam que se perpetuou durante 77 anos uma concentração econômica regional de mais de 50\% do PIB nacional na regiāo Sudeste. Conforme dados do IBGE, apresentado na Tabela 01 , houveram mudanças, porém, mantendo a enorme concentração espacial da riqueza.

Tabela 01: Distribuição relativa dos PIB’s regionais 1939-2016 (Períodos selecionados)

\begin{tabular}{l|c|c|c|c|c|c|c|c|c}
\hline Regióes & $\mathbf{1 9 3 9}$ & $\mathbf{1 9 5 0}$ & $\mathbf{1 9 6 0}$ & $\mathbf{1 9 7 0}$ & $\mathbf{1 9 8 0}$ & $\mathbf{1 9 9 0}$ & $\mathbf{2 0 0 0}$ & $\mathbf{2 0 1 0}$ & $\mathbf{2 0 1 6}$ \\
\hline Norte & 2,7 & 1,7 & 2,2 & 2,3 & 3,3 & 4,9 & 4,6 & 5,3 & 5,4 \\
Nordeste & 16,7 & 14,6 & 14,8 & 12 & 12,2 & 12,9 & 13 & 13,5 & 14,3 \\
Sudeste & 63,2 & 65,6 & 62,8 & 65 & 62,1 & 58,8 & 57,5 & 56,1 & 53,2 \\
Sul & 15,3 & 16,3 & 17,8 & 17 & 17,3 & 18,2 & 17,7 & 16,0 & 17,0 \\
Centro-Oeste & 2,1 & 1,8 & 2,4 & 3,7 & 5,1 & 5,2 & 7,2 & 9,1 & 10,1 \\
\hline
\end{tabular}

Fonte: Alves (2020, p. 26).

A maior composição do PIB brasileiro no período apresentado acima, foi fortemente concentrado na Regiáo Sudeste, com extensa participação do estado de São Paulo. Contudo 
essa participação vem caindo ao longo dos anos reduzindo a concentração espacial e, consequentemente as desigualdades regionais. Porém medidas devem ser tomadas como forma de planejar um processo e desenvolvimento regional que viabilize não só as reduções das disparidades regionais, mas sobretudo das desigualdades sociais dentro de cada região.

Para além da unificação dos mercados nacionais, nos últimos anos, sobretudo de 1990 a 2016, observa-se que a participação na composição do PIB regional é quase dobrada na região Centro-Oeste, passando de 5,2\% para 10,1\%, isso pode ser explicado pelo fato de que houve uma participação elevada no que diz respeito a comercialização de commodities, aumento da produção de agrícola e geração de novos postos de trabalho.

No Norte e Nordeste o aumento nesse período foi de apenas 0,5\% e 0,8\% respectivamente. E no Sul e Sudeste há uma redução da participação na composição do PIB em 58,8\% para 53,2\% no Sudeste e $17,7 \%$ para $17 \%$ no Sul. Segundo Alves (2020), não necessariamente $\mathrm{o}$ valor de suas produçóes tenham sido reduzidos, mas em termos agregados, começam a perder espaço. Muito embora, essas duas regióes concentrem mais de $70 \%$ do PIB do país.

\section{Procedimento Metodológico}

Objetivou-se mensurar os desequilíbrios intra e inter-regional brasileiros nas últimas três décadas e analisá-los partindo da hipótese de convergência do desenvolvimento introduzida pelo clássico trabalho de Williamson (1965). Para tanto, foram utilizadas variáveis censitárias da população nacional e dos estados brasileiros, além da variável renda per capita nos anos de 1991, 2000 e 2010. Os dados, de natureza secundária, foram extraídos do Censo Demográfico, disponibilizado pelo Instituto Brasileiro de Geografia e Estatística (IBGE).

Com o fito de captar traços de redução das desigualdades regionais no território, utilizou-se o Índice de Williamson $\left(\boldsymbol{V}_{\boldsymbol{w}}\right)$. Em termos formais esse índice é composto por:

$$
V_{w}=\frac{\sqrt{\sum_{i}\left(y_{i}-\bar{y}\right)^{2} \frac{f_{1}}{n}}}{\bar{y}}
$$

onde: $\boldsymbol{f}_{\mathbf{1}}$ é população da i-ésima região; $\boldsymbol{n}$ é população nacional; $\boldsymbol{y}_{\boldsymbol{i}}$ é renda per capita da i-ésima região e $\overline{\boldsymbol{y}}$ e renda per capita nacional. Este índice varia de 0 a 1 onde valores próximos a 0 dizem respeito a menos desigualdades e valores próximos a 1 representa mais desigualdades.

Em que pese, o resultado esperado é que a descrição estatística da desigualdade regional tenha a forma de um $\mathrm{U}$ invertido, ao longo do curso do crescimento nacional, conforme Williamson (1965). Esse formato é ilustrado pela Figura 01. 
Figura 01: $U$ invertido aumentado

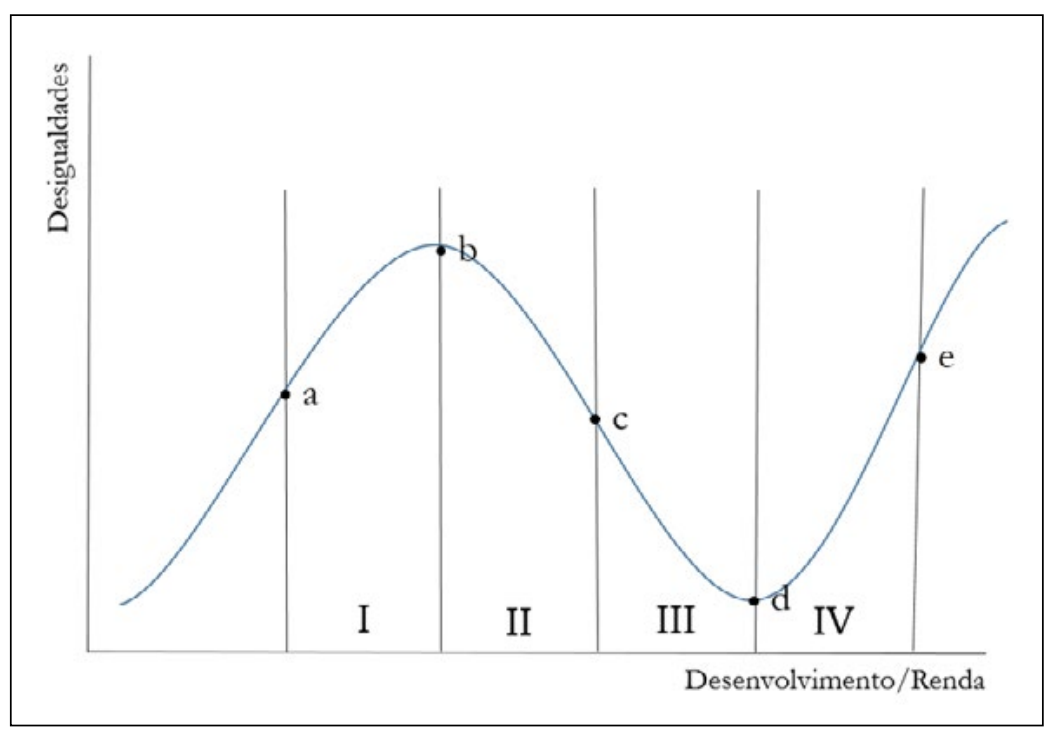

Fonte: Elaboração própria com base em Amos Jr. (2014, p.523).

A Figura 01, é uma tentativa de ilustrar a lógica do U invertido de Kuznets, mostra uma relação inversamente proporcional entre Desigualdades e Desenvolvimento/Renda. A ideia, segundo Amos Jr. (2014), é a de que na medida em que a renda per capita aumenta durante o período, esses resultados indicam que a desigualdade de renda regional está aumentando e divergindo, subindo a primeira perna (a) (ou mais provavelmente a terceira perna (e)) de um $U$ invertido de Kuznets, presumivelmente entre o segmento inicial e I e no segmento IV da Figura 01.

Silva et al. (2010) atribui esse argumento ao fato de que o momento histórico do máximo de desigualdade espacial é um tanto quanto vago, e pode variar consideravelmente com a dotação de recursos e o ambiente institucional de cada nação em desenvolvimento.

\section{Resultados e Discussão}

Levando em consideração todo o Brasil como uma unidade de análise, o índice de Williamson foi calculado com base nas cinco regiōes e nos estados, para o período de 1991, 2000 e 2010. O objetivo é examinar as desigualdades regionais brasileiras tanto a partir da perspectiva inter-regional e intra regional.

Como se observa pelo Gráfico 01, ao aplicar ao Brasil, nota-se o formato do U invertido da Teoria de Williamson, isso é, ilustra um padráo hipotético de desigualdade de renda regional sugerido pela teoria dos ciclos dos polos de crescimento (PERROUX, 1955), estendendo a hipótese básica de U invertido de Kuznets (KUZNETS, 1955). O primeiro segmento da curva, de 1991 a 2000, apresenta o padráo de Kuznets U-invertido de divergência e convergência. Em 2010, a curva atinge um valor mínimo e a tendência é começa a aumentar, refletindo novamente a divergência de renda regional. 


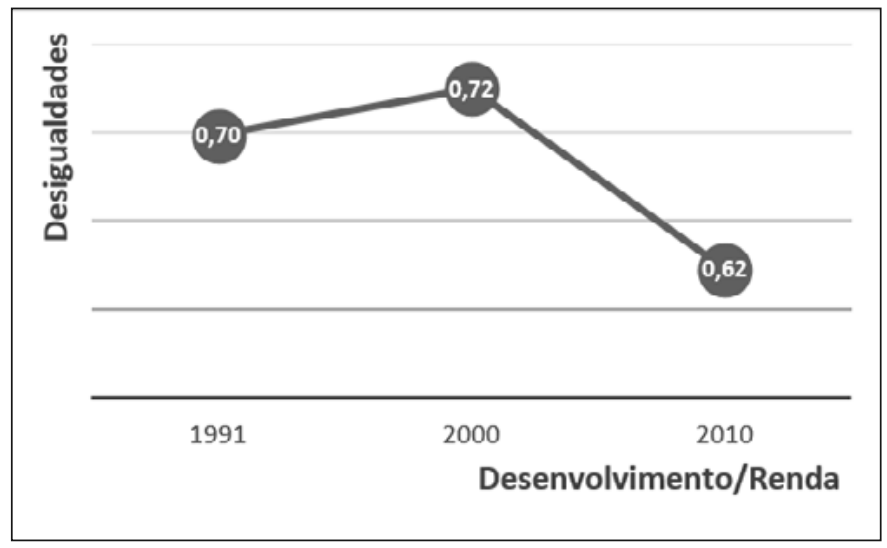

Fonte: Elaboração própria a partir dos resultados.

É evidente que os diferenciais na renda tanto reduziram no período de 1991 e 2010 , mostrando uma variação percentual de aproximadamente $11,4 \%$. No que diz respeito à variação de um período para o outro, observou-se uma significativa mudança e uma redução das desigualdades. Entre 1991 e 2000, houve uma leve elevação de aproximadamente 3\% e entre 2000 e 2010 uma redução das desigualdades de aproximadamente 14\%. Nesse último caso, muito dessa redução pode ser explicado pelas políticas de cunho desenvolvimentistas com estímulo ao consumo e demanda agregada, havendo ampliação da renda per capita. Segundo Alves (2020) do ano 2000 até 2010, destaca-se uma queda substancial das taxas de desemprego, muito disso se deve em açóes desenvolvimentistas e um período onde a conjuntura nacional apresentava sinais de estabilidade e crescimento econômico.

Uma colaboração visando a redução das disparidades regionais, segundo Araújo (2013), se deu com o governo Lula. Segundo a autora, o governo Lula termina com uma proposta de formulação nova para a política nacional de desenvolvimento regional (PNDR), que embute avanços, como o de reconhecer que a desigualdade regional no Brasil não pode ser tratada apenas na escala macrorregional (o que leva as políticas regionais a priorizar apenas o Nordeste e Norte do país) e, portanto apontava para a importância de considerar o problema em outras escalas, o que levaria a sub-regióes do Sul e mesmo do Sudeste à agenda prioritária da política federal (ARAÚJO, 2013).

De acordo com Brandão (2019), no período 2003-2015, ocorreu intensa reconfiguração inter-regional no Brasil, mas sobretudo na escala intrarregional de suas cinco macrorregióes. Em razão da nossa avançada agenda de política social e de infraestrutura levada a cabo recentemente, o problema regional tomou outra dimensão.

Em termos de desigualdades intra regionais, as regióes Norte e Centro-Oeste apresentaram aumento da concentração de renda per capita. Já o Nordeste, Sul e Sudeste apresentaram resultados interessantes e importantes no tocante da redução das desigualdades dentro de seus próprios territórios. Por meio do índice de Williamson calculado, observou-se que a região Norte apresentou uma variação percentual de diminuição das desigualdades de 
21,9\% no período de (1991-2000) e um aumento das desigualdades, ou seja, concentração de renda, em aproximadamente $24 \%$ no período entre 2000 e 2010 . O que gera, no final, uma queda de $3,13 \%$.

Já a regiāo Centro-Oeste, os resultados mostram que é a região com maior taxa de concentraçẫo de renda do país. Nos três anos de análise, a queda das desigualdades no período de 1991 a 2010, em média, foi de aproximadamente 4,8\%, sendo que entre 1991 a 2000 caiu em aproximadamente 9,5\%, e entre 2000 e 2010 houve um aumento de 5,3\%.

A concentração de renda nessas regióes (Norte e Centro-Oeste), cresce muito em função de suas próprias características. No caso do Norte, é uma regiāo que, geograficamente, além de ser distante dos grandes polos nacionais (o eixo Sul-Sudeste) é uma regiáo com de grande área territorial, a maior do país, o que dificulta o deslocamento pendular e facilita a promoção de concentraçấo não só em termos de renda, mas também populacional.

No Centro-Oeste, além de características "interioranas" como a ausência do litoral, há de considerar o que Alves (2020, p.40) destacou: "O Distrito Federal, devido entre outros fatores, a renda média dos funcionários públicos que ali vivem apresenta renda média maior que o dobro da renda média nacional e do que os outros estados da regiáo".

A região Nordeste do Brasil, uma regiáo historicamente mais atrasada devido a vários fatores, observou-se uma queda das desigualdades de renda pela perspectiva intra regional. Entre os anos de 1991 e 2000, a reduçáo foi de 13,9\% e entre 2000 e 2010 foi de 12,9\%, o que representa uma diminuiçấo total das desigualdades de renda per capita de $25 \%$. No estudo de Pereira (2015), o Nordeste participou da guerra fiscal, mas que as demais regiōes também participaram, levadas pelas pressóes de um capital que se reestruturava e que procurava novos espaços produtivos no qual a taxa de lucro mantivesse nos níveis de concorrência global, devido principalmente a abertura comercial dos anos 1990. No entanto, outras regiôes, em particular, o Sul e Sudeste participaram mais ativamente, mesmo que a proporção de incentivos parafiscais fosse superior aos fiscais, quando comparado com o Nordeste.

O fato é que os ganhos do Nordeste não foram tão significativos para a totalidade da região, quanto o foram para determinadas unidades da federação (PEREIRA, 2015). Assim, muito embora haja uma queda acentuada das desigualdades intra regionais no Nordeste, essa queda comparada às regiốes Sul e Sudeste foi em uma dimensão menor, porém importante para o processo de desenvolvimento local e regional. 
Gráfico 02: Desigualdades intra regionais brasileiras (1991/2000/2010)

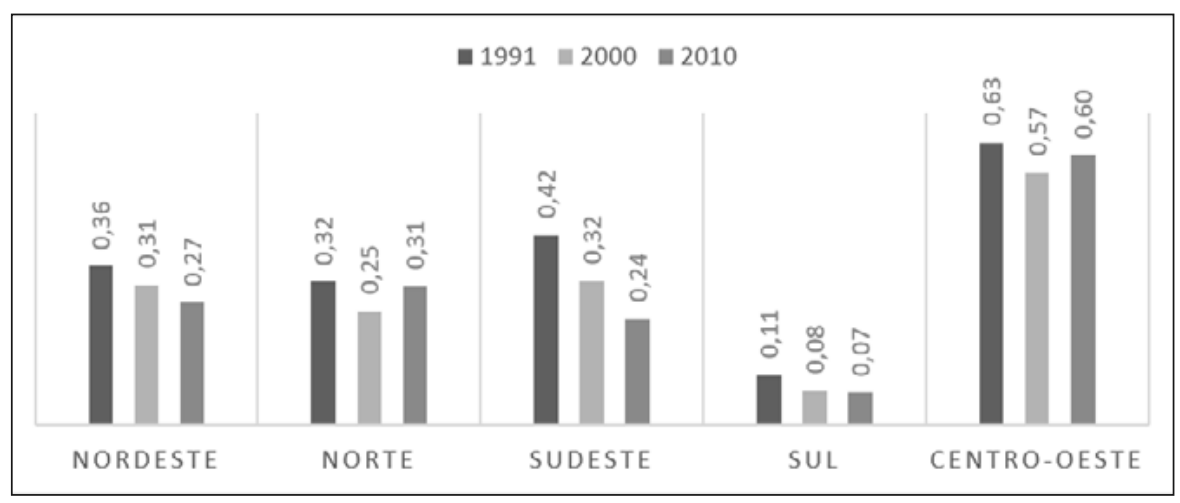

Fonte: Elaboração própria a partir dos resultados.

No caso do Sudeste, uma das regiōes mais impactadas devido ao processo de reestruturação produtiva em meados da década de 90, esta apresentou as maiores taxas de redução desigualdades regionais. Nesse ínterim, entre 1991 e 2000 a diminuição foi de $23,8 \%$ e entre 2000 e 2010 foi de $25 \%$. Por fim, a região apresenta, em termos de variaçáo percentual do índice de Williamson, uma queda de 42,9\% das desigualdades regionais a maior dentre todas as regióes. Já no Sul do país, observa-se que há uma baixa concentração, muito embora essa ainda caia no período de análise de 27,3\% (1991-2000) e 12,5\% (20002010), expressando uma queda total de aproximadamente $36,4 \%$.

Dentre os resultados destacados, evidências que a renda per capita em um contexto nacional foi se elevando com o passar dos anos, sobretudo entre 2000 e 2010. A Tabela 02, mostra a evolução da razão entre a renda domiciliar dos mais ricos e mais pobres de 2001 a 2009.

Tabela 1 - Razão entre renda domiciliar per capita dos 20\% mais ricos e $20 \%$ mais pobres (2001-2009)

\begin{tabular}{lccccccccc}
\hline Regióes & $\mathbf{2 0 0 1}$ & $\mathbf{2 0 0 2}$ & $\mathbf{2 0 0 3}$ & $\mathbf{2 0 0 4}$ & $\mathbf{2 0 0 5}$ & $\mathbf{2 0 0 6}$ & $\mathbf{2 0 0 7}$ & $\mathbf{2 0 0 8}$ & $\mathbf{2 0 0 9}$ \\
\hline Centro-Oeste & 23,7 & 23,3 & 22,0 & 19,4 & 20,3 & 18,2 & 19,6 & 18,9 & 18,0 \\
Norte & 19,7 & 18,9 & 17,2 & 16,6 & 15,4 & 14,8 & 16,7 & 14,5 & 15,6 \\
Nordeste & 24,8 & 22,5 & 22,4 & 21,3 & 20,2 & 20,6 & 21,0 & 19,2 & 19,8 \\
Sul & 19,3 & 16,9 & 16,9 & 16,1 & 15,5 & 14,6 & 14,6 & 13,8 & 13,5 \\
Sudeste & 22,1 & 20,4 & 20,1 & 17,9 & 17,6 & 16,8 & 16,0 & 15,2 & 14,7 \\
\hline Brasil & $\mathbf{2 7 , 5}$ & $\mathbf{2 5 , 0}$ & $\mathbf{2 4 , 7}$ & $\mathbf{2 2 , 4}$ & $\mathbf{2 1 , 7}$ & $\mathbf{2 0 , 8}$ & $\mathbf{2 0 , 7}$ & $\mathbf{1 9 , 3}$ & $\mathbf{1 9 , 0}$ \\
\hline
\end{tabular}

Fonte: Elaboração própria a partir de IPEA (2020).

Observa-se que o Nordeste apresentou a menor redução na diferença entre a renda dos mais ricos em relação a dos mais pobres: 20,2\%, uma vez que a razão entre a renda desses estratos passou de 24,8 em 2001 para 19,8 em 2009, a maior proporção entre as 
macrorregióes, sendo considerada a regiáo com maior concentração de renda do país. Já o Sul apresenta a menor concentração de renda e o Sudeste a menor redução da diferença de renda entre ricos e pobres nesse período, de 33,5\%. Conforme analisado por Baptistella, Souza e Ferreira (2011), o Norte e Centro-Oeste, tiveram suas reduçóes em torno de 20,8\% e $24 \%$, respectivamente.

O Gráfico 03 apresenta os estágios das desigualdades intra regionais. Pelas características, a maioria das regiōes se encontram em 1991, no ponto (d). Entre 1991-2000 todas apresentaram um momento de redução, equivalendo aos estágios II e III. No caso especifico das regióes Norte e Centro-Oeste o ano de 2000, a curva atinge um valor mínimo e a tendência é começa a aumentar, refletindo novamente a divergência de renda regional.

Gráfico 03: $U$ invertido das Desigualdades intra regionais

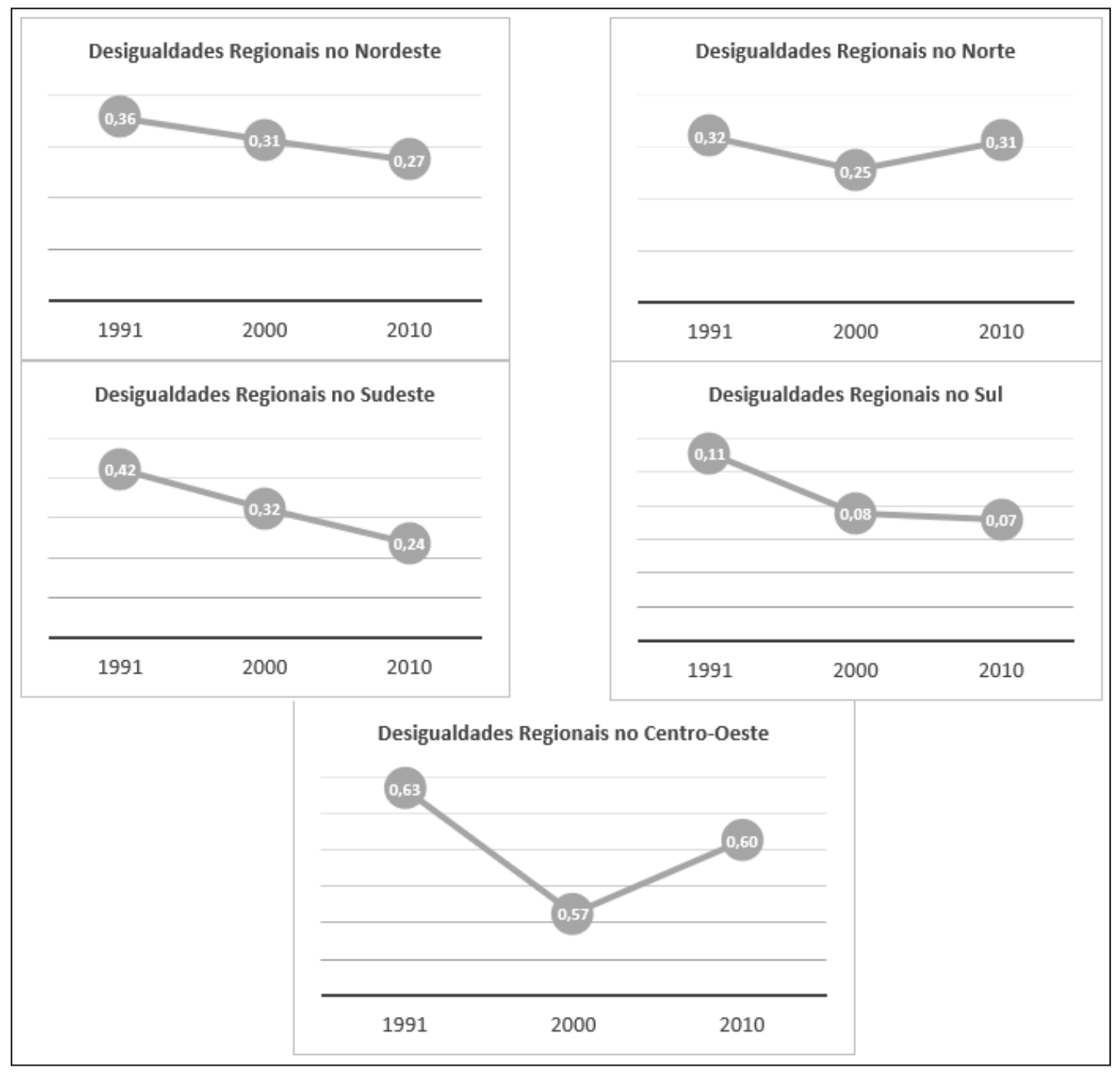

Fonte: Elaboração própria a partir dos resultados. 
Assim como apontado por Silva et al. (2014) é significativo o fato de que as regióes Nordeste, Norte e Centro-Oeste, estejam, ao que tudo indica, na primeira fase do modelo de Williamson, a do crescimento com desequilíbrios regionais. As regiōes Sul e Sudeste podem ser classificadas na segunda fase do modelo, onde os desequilíbrios são bem menos expressivos, indicando uma maior convergência do desenvolvimento.

\section{Consideraçóes Finais}

O trabalho mensurou os desequilíbrios intra e inter-regionais brasileiros partindo da hipótese de convergência do desenvolvimento introduzida por Williamson em 1965. Observou-se que de forma inter-regional houve uma queda acentuada nos anos pós-2000 das desigualdades regionais. Isso representa uma maior renda per capita nacional, bem como queda na concentração de renda. Contudo, de forma intra regional, observou-se um aumento das disparidades regionais, sobretudo, no Norte e Centro-Oeste, enquanto que no Nordeste, Sul e Sudeste notou-se uma queda importante no índice de Williamson indicando uma maior convergência do desenvolvimento.

Por meio da análise dos desajustes regionais brasileiros, observou-se dois agrupamentos, o primeiro com Nordeste, Norte e Centro-Oeste, em que indicam estar na primeira fase do modelo de Williamson, a do crescimento com desequilíbrios regionais. Já um segundo agrupamento compreendendo as regióes Sul e Sudeste, estas podem ser classificadas na segunda fase do modelo, onde os desequilíbrios são bem menos expressivos, indicando uma maior convergência do desenvolvimento.

Assim, a hipótese de Williamson é aceita para três regióes do país onde se notou redução das disparidades compreendendo em uma maior convergência do desenvolvimento, muito embora seja mais próxima a convergência das regiōes Sul e Sudeste. No caso da região Nordeste, há de considerar um longo percurso na tentativa de reduzir as desigualdades dentro do seu território e ainda a disparidade econômica em relação as demais regióes.

Já as regióes Norte e Centro-Oeste estão crescendo ainda com fortes desequilíbrios regionais, conforme se observou no período compreendido entre 2000 e 2010. Uma justificativa que pode estar associada a esse crescimento desequilibrado pode estar associada a dimensão territorial e a dificuldade de locomoção dentro dos limites da regiáo Norte, como: i) bacia hidrográfica, ii) canais fluviais, iii) floresta da Amazônia e iv) áreas protegidas e terras indígenas. No caso do Centro-Oeste, conforme destacado por Alves (2020), devido entre outros fatores, a renda média dos funcionários públicos no Distrito Federal que ali vivem apresenta renda média maior que o dobro da renda média nacional e do que os outros estados da regiâo. Demonstrando uma nítida concentração em termos de rendimentos regionais e fortes disparidades intra regionais.

Contudo, é importante reconhecer e indicar estudos futuros que abordem uma análise histórica bem mais longa para se poder comprovar a hipótese de Williamson. Além do mais, sugere-se para pesquisas futuras, trabalhar com outros recortes espaciais objetivando identificar maiores características desse processo de desigualdade regional no território brasileiro, não só em termos regionais, mas pela ótica de cada estado ou mesmo dos municípios. Outro ponto importante a ser destacado, é que o exercício espacial pode 
ajudar a compreender a dinâmica da economia da regiáo em seus aspectos locacionais. Espera-se que estudos como este balizem iniciativas do ponto de vista estratégico ao se pensar em política nacional de desenvolvimento regional, que compreenda as dificuldades e as vantagens de cada região, servindo como ponto de apoio ao planejar políticas públicas de infraestrutura, qualidade de vida, melhorias dos serviços públicos, nas condiçóes de trabalho da população entre outros.

\section{Referências}

\section{ALVES, D. F. Estrutura Produtiva e Desigualdade Intermunicipal de Renda no}

Brasil: uma abordagem regional. 205p. Dissertação (Mestrado em Economia) - Centro de Ciências Sociais Aplicadas, Universidade Federal do Rio Grande do Norte, Natal, 2020.

AMOS JR, Orley M. Evidence of Increasing Regional Income Variation in the United States: 1969-2006. Modern Economy, v. 5, n. 05, p. 520, 2014.

\section{ARAÚJO, T. B. Pacto federativo, integração nacional e desenvolvimento regional.} São Paulo: Perseu Abramo. Tendências do desenvolvimento regional recente no Brasil, p. 39-52. 2013

BALDWIN, R.E. Patterns of development of newly settled regions. Manchester School of Economics and Social Studies, v. 28, May, 1956.

BAPTISTELLA, J. C. F.; SOUZA, S. C. I.; FERREIRA, C. R. Queda na desigualdade de renda das macrorregióes brasileiras: a participação dos programas de transferência monetária no período 2001-2009. Brasília: IPEA. 2011.

BERCOVICI, Gilberto. Desigualdades regionais, Estado e Constituiçáo. São Paulo: Max Limonad, 2003.

BRANDÃO, C. A. Dinâmicas e transformaçóes territoriais recentes: o papel da PNDR e das políticas públicas não regionais com impacto territorial. IPEA - Texto para Discussão, n. 2460. 2019. Disponível em: <https://bit.ly/3aCWdla>. Acesso em: 02 mai. 2020.

CANO, W. Desconcentração produtiva regional do Brasil - 1970-2005. São Paulo: Editora UNESP, 2008.

CASTRO, Iná Elias de. O mito da necessidade: discurso e prática do regionalismo nordestino. Rio de Janeiro: Bertrand Brasil, 1992.

COUTINHO, Luciano. Desigualdades regionais uma revisão da literatura. Revista de Administração de Empresas, v. 13, n. 3, p. 63-73, 1973. 
FARGION, V. From the southern to northern question- territorial and social politics in Italy Università di Firenzi, 2004.

FURTADO, Celso. O Brasil Pós Milagre. 7 ed. Rio de Janeiro: Paz e Terra, 1982.

GAMA, M.L.; BARACHO, H.U. A formação da desigualdade regional, suas premissas e a questão do nordeste brasileiro. Direito e Desenvolvimento, v. 5, n. 10, p. 235-254, 2014.

GRIBAUDI, G. Images of the South - The Mezzogiorno as seen by insiders and outsiders. In LUMBLEY, R.; MORRIS, J. (Eds.): The New History of the Italian South The Mezzogiorno Revisited, 1997.

HADDAD, P. R.; et al. (Org.). Economia Regional: teoria e métodos de análise. Fortaleza: Banco do Nordeste do Brasil, 1989.

IPEA. IPEADATA. Dados e indicadores sobre renda, pobreza e extrema pobreza. Disponível em: < https://bit.ly/2xts3CJ>. Acesso em: 02 mai. 2020.

ISARD, W. Introduction to regional science. Englewood Cliffs, New Jersey: Prentice Hall, 1975.

ISARD, W. Location and spaceeconomy. New York: MIT - John Wiley \& Sons, 1956.

KUZNETS, S. Economic growth and income inequality. American Economic Review, v. 45 , n. $1,1955$.

MARIANO, K. L. P.; LUCIANO, B. T. Implicaçóes nacionais da integração regional: as eleições diretas do parlamento do Mercosul. In: DESIDERÁ NETO, Walter Antonio Organizador. O Brasil e novas dimensões da integração regional. Brasília: IPEA, p.145182, 2014.

MERHAV, M. Technological depenãence, monopoly and growth. N. York, Pergamon Press, 1970.

MONASTERIO, Leonardo. Fronteira de Disparidade Regional. Análise Econômica, v. 32, n. 62, 2014.

MYRDAL, G. Rich lands and poor. New York, Vintage Books, 1966.

PEREIRA, William Eufrásio Nunes. O desenvolvimento econômico e a redução das desigualdades regionais enquanto princípios constitucionais desrespeitados por políticas incentivadoras da guerra fiscal. 2018. Trabalho de Conclusão de Curso.

Universidade Federal do Rio Grande do Norte. 2018 
PEREIRA, William Eufrásio Nunes. REESTRUTURAÇÃO ECONÔMICA NO NORDESTE BRASILEIRO. Revista de Economia Regional, Urbana e do Trabalho, v. 04, p. 59-66, 2015.

PERROUX, F. Notes sur la notion de pôle de croissance. Economie appliquée, n. 8, p. 307-322, 1955. Disponível em: <https://bit.ly/33SLWPh>. Acesso em: 02 mai. 2020.

RICHARDSON, H. W. Polarization reversal in developing countries. Papers of the Regional Science Association, v. 45, p. 67-85, 1980.

SILVA, B. M., et al. Desequilíbrios Regionais No Brasil e a Hipótese da Convergência do Desenvolvimento. RDE-Revista de Desenvolvimento Econômico, v. 12, n. 22, 2011.

SILVA, J. R. A teoria da polarização como instrumento de programação econômica a nível regional. RDE-Revista de Desenvolvimento Econômico, v. 1, n. 2, 2009.

VIETORISZ, T. The planned interregional location of industry: argument in favor of a "trade-not-aid" approach. United Nations Industriai Review of Organization, p. 1-60, Sep. 1967.

WILLIAMSON, Jeffrey G. Regional inequality and the process of national development: a description of the patterns. Economic development and cultural change, v. 13, n. 4, Part 2, p. 1-84, 1965. 